\title{
Pelatihan Menumbuhkan Karakter Siswa Sekolah Dasar Tanjung Sari Melalui Permainan Edukatif Sederhana
}

\author{
Rahmiati $^{1}$, Mimin Minawati ${ }^{1}$ dan Sri Lestari Handayani ${ }^{1}$ \\ ${ }^{1}$ Universitas Muhammadiyah Prof Dr Hamka, Jl. Tanah Merdeka, Jakarta Timur, DKI Jakarta, Indonesia, \\ 13830 \\ Email*: rahmiatizen@gmail.com
}

\begin{abstract}
Abstrak
Pelatihan menumbuhkan karakter siswa Sekolah Dasar Tanjung Sari melalui permainan edukatif sederhana ini bertujuan untuk menunjukan kesenjangan antara harapan dan kenyataan yang perlu pemecahan masalah yang mendasar, melalui permainan edukatif untuk menanamkan karakter pada anak. Permainan yang diberikan ada tiga macam, diantanya; tepuk bim bam pedi, talking stick, dan kuda bisik. Dari ketiga permainan diatas yang merupakan permainan yang cukup sederhana dapat di aplikasi kedalam kegiatan belajar mengajar baik didalam kelas maupun diluar kelas.sehingga tidak hanya kesenangan semata yang didapatkan dalam permainan. Namun permainan mampu memberi manfaat yang besar bagi anak. Tidak kalah pentingnya, permainan dapat membentuk anak menjadi seseorang yang memiliki karakter luhur. Nilai-nilai karakter yang terdapat dalam permainan edukatif sederhana ini diantaranya: kerjasama, kekompakan, toleransi, kejujuran, kedisiplinan, rasa ingin tahu, semangat kebangsaan, menghargai, kepemimpinan, peduli lingkungan, peduli sosial, tanggung jawab, religius, dan gemar membaca. Melalui kegiatan pengabdian yang dilakukan oleh guru dapat meningkatkan (1) pengetahuan guru dalam membuat permainan sederhana pada saat pembelajaran (2) guru dapat termotivasi untuk membuat permainan sederhana di dalam kelas. (3) kemampuan guru dalam menerapkan permainan sederhana supaya siswa berkarakter (4) guru dapat menambah pengetahuan tentang permainan sederhana.
\end{abstract}

Kata kunci: pendidikan karakter, permainan edukatif sederhana

\begin{abstract}
The training fosters the character of Tanjung Sari Elementary School students through this simple educational game aimed at showing the gap between expectations and reality that needs to solve fundamental problems, through educational games to instill character in children. The game given there are three kinds, among them; bim bam pedi pats, talking sticks and kuda bisik. Of the three games above which are fairly simple games can be applied into teaching and learning activities both in the classroom and outside the classroom. But the game can provide great benefits for children. No less important, the game can shape the child into someone who has a noble character. Character values contained in this simple educational game include: collaboration, cohesiveness, tolerance, honesty, discipline, curiosity, national spirit, respect, leadership, care for the environment, social care, responsibility, religious, and love to read. Through service activities conducted by the teacher can increase (1) teacher knowledge in making simple games during learning (2) teachers can be motivated to make simple games in the classroom. (3) the teacher's ability to apply simple games so that students have character (4) teachers can increase knowledge about simple games.
\end{abstract}

Keywords: character education, simple educational games

Format Sitasi: Rahmiati, Minawati, M. \& Handayani, S. L. (2020). Pelatihan Menumbuhkan Karakter Siswa Sekolah Dasar Tanjung Sari Melalui Permainan Edukatif Sederhana. Jurnal SOLMA, 09(1), 231-238. Doi: http://dx.doi.org/10.29405/solma.v9i1.3920

Diterima: 23 November 2019 | Revisi: 29 Maret 2020 | Dipublikasikan: 30 April 2020 
(C) 2020 Oleh authors. Lisensi Jurnal Solma, LPPM-Uhamka, Jakarta. Artikel ini bersifat open access yang didistribusikan di bawah syarat dan ketentuan Creative Commons Attribution (CC BY) license. (http://creativecommons.org/licenses/by/4.0/).

\section{PENDAHULUAN}

Pendidikan merupakan kunci utama untuk menumbuhkan karakter siswa pada proses pembelajaran maupun kemampuan siswa menerimaan informasi dan pengetahuan tentang perilaku yang baik dan buruk. Pendidikan karakter merupakan salah satu tujuan pendidikan nasional yang bertujuan untuk membina generasi muda menjadi manusia yang beretika, cerdas dan berakhlak mulia. Sehingga hal ini menguatkan pondasi kebangsaan menuju bangsa yang lebih baik. Menurut Khamalah (2017), pendidikan karakter erat kaitannya dengan pembinaan moral. Karakter berkaitan dengan konsep moral (moral knowing), sikap moral (moral felling), dan perilaku moral (moral behavior) (Lickona, 1991; Lickona, 2015; Dalmeri, 2014).

Namun mengenalkan dan menumbuhkan karakter bukan hal yang mudah yang dapat langsung didapatkan. Hal ini sejalan dengan pendapat Dewi \& Handayani (2019), bahwa pendidikan itu sendiri merupakan sikap sadar dan disengaja untuk mengembangkan potensi yang ada dalam diri anak, salah satunya adalah kekuatan karakter. Pada penanaman nilai-nilai karakter pada siswa diperlukan melalui permainan edukatif sederhana, yang pada dasarnya usia siswa sekolah dasar merupakan tingkat usia yang berada pada tahap bermain (Abdullah, Hastuti, \& Karmila, 2016).

Guru memiliki tugas dalam mencapai tujuan pembelajaran dengan melakukan pengelolaan pembelajaran dimulai dari perencanaan, pelaksanaan, hingga pada penilaian. Hal ini ditujukan agar siswa dapat mencapai pada tujuan pembelajar, Terlebih dalam pembelajaran guru dituntut untuk mendemonstrasikan dan menunjukkan proses kreatifitas. Kreatifitas menunjukkan bahwa apa yang akan dikerjakan oleh guru sekarang lebih baik dari yang telah dikerjakan sebelumnya.

Proses pembelajaran yang sudah dikelola atau direncanakan oleh guru mulai dari langkah awal perencanaan sampai pada langkah penilaian seorang guru harus kreatif dengan tujuan untuk membangkitkan dan menumbuhkan karakter siswa. Salah satunya dengan menyisipkan permainan edukatif yang sederhana untuk peralihan situasi dari yang membosankan, atau kondisi tegang menjadi ceria dan menyenangkan.

Permainan edukatif sederhana bagi siswa tidak harus yang mahal bahkan selaras dengan pendapat Astini, Nurhasanah, Rachmayani, \& Suarta (2017) yaitu permainan 
edukatif merupakan permainan yang dapat menstimulasi panca indra, dan kecerdasan. Meliputi indra pengelihatan, penciuman, pengecapan, perabaan, dan pendengaran. Akan tetapi tidak haruslah mahal, kita bisa membuat sendiri dengan memanfaatkan bendabenda yang ada disekitaran kita (Astini et al., 2017). Sehingga menimbulkan karakter yang diharapkan seperti tanggungjawab, jujur, dan meningkatkan interaksi sosial serta menimbulkan rasa senang dan semangat dalam menerima pembelajaran atau informasi. Permainan yang dikenalkan sebagai berikut; (1) Tepuk bim bam pedi, (2) Talking stick, (3) Kuda bisik.

Melalui observasi yang peneliti lakukan bahwa pada Sekolah Dasar Tanjung Sari, permainan edukatif belum dipergunakan dengan baik khususnya dalam proses pembelajaran baik sebelum dan sesudah pembelajaran. Berdasarkan fenomena yang menunjukkan kesenjangan antara harapan dan kenyataan maka peneliti memandang perlunya solusi pemecahan masalah yang mendasar, melalui permainan edukatif untuk menanamkan karakter pada anak, berikut ini pelatihan yang diterapkan dengan melakukan permainan edukatif sederhana kepada siswa agar, siswa tersebut tertarik melaksanakan pembelajaran baik sebelum, sesudah ataupun saat proses pembelajaran.

\section{MASALAH}

Permasalahan yang dihadapi oleh sekolah mitra saat ini adalah: Metode pendidikan terlalu fokus pada ilmu pelajaran dan tidak memperhatikan pendidikan karakter, kurangnya pemahaman penggunaan teknologi yang mengakibatkan penurunan pendidikan karakter pada generasi muda. Serta berkurangnya daya kreatifitas yang dialami oleh guru, yang disebabkan oleh banyaknya peraturan dan tugas kewajibannya di luar memperoses pembelajaran di kelas.

\section{METODE PELAKSANAAN}

Solusi permasalahan yang ditawarkan dalam pengabdian masyarakat ini, yaitu: dengan menetapkan peserta dalam PKM yaitu guru yang mengajar dan siswa SD Tanjung Sari, Magelang dengan menerapkan permainan sederhana yang dapat dilaksanakan baik dalam kelas maupun diluar kelas. Kegiatan yang dilakukan selama dua hari pada tanggal 25-26 Februari 2019.

Dalam rencana pengabdian ini berupa nilai karakter melalui permainan sederhana bagi siswa SD Tanjung Sari, Magelang, Jawa Tengah. Kegiatan dilaksanakan selama 2 hari dengan peserta guru-guru dan siswa di sekolah tersebut. Setelah diberikan pengarahan 
tentang cara bermain, peserta diminta untuk mengikuti permainan yang telah diarahkan olalu didiskusikan dengan tanya jawab sehingga peserta paham akan nilai dan manfaat permainan yang dimainkan. Adapun langkah kegiatan yang dilaksanakan adalah sebagai berikut ini:

1. Paparan materi

Paparan materi yang disesuaikan dengan materi pembelajaran yang sedang dilaksanakan agar mempermudah permainan edukatif, karena permainan ini membantu siswa untuk mengevaluasi atau memahami sejauh mana siswa menerima informasi dan materi yang telah disampaikan.

2. Pelatihan

Kegiatan ini akan mengajak siswa untuk melakukan intrukur atau perintah dan peraturan dari permainan edukatif ini. Tujuan kegiatan ini adalah untuk membangun karakter siswa yang diharapkan, seperti tanggungjawab, jujur, kepekaan, dan solidaritas dalam berkelompok. Adapun langkah-langkah yang akan dilakukan terkait dengan pelatihan ini adalah:

a. Tahap persiapan, meliputi:

1) Identifikasi masalah kebutuhan dan kemampuan siswa SDN Tanjung Sari.

2) Melakukan analisis masalah untuk mendapatkan solusi yang tepat untuk mengatasi karakter siswa.

b. Tahap pelaksanan, meliputi:

Paparan materi dan pelatihan dalam pelaksanaannya siswa SDN Tanjung Sari sebagai peserta aktif. Pada sesi paparan materi dan pelatihan yang akan disampaikan, peserta akan diberi kesempatan untuk melakukan percobaan sebelum diterapkannya permainan edukatif. Berikut kerangka berpikir program pengabdian masyarakat "Menumbuhkan Karakter Siswa Sekolah Dasar Tanjung Sari melalui Permainan Edukatif Sederhana".

c. Tahap evaluasi, meliputi:

Tahap evaluasi yang dilakukan pada kegiatan pengabdian ini dengan melakukan diskusi dan wawancara tidak terstruktur kepada kepala sekolah dan guru SDN Tanjung Sari, Magelang Jawa Tengah tersebut terkait dengan kegiatan selama dua hari yang dilakukan. Dalam kegiatan evaluasi dilakukan secara santai setekah kegiatan hari kedua selesai. Berdasarkan hasil evaluasi diperoleh beberapa informasi yang didapatkan, diantaranya (1) guru secara lisa menyambut baik dalam 
kegiatan pengabdian ini, (2) siswa terlihat antusias dengan permainan yang dilakukan didalam kelas, (3) guru termotivasi untuk dapat melaksanakan kegiatan permainan sederhana pada saat pembelajaran berlangsung.

\section{HASIL DAN PEMBAHASAN}

. Hasil pengabdian "PKM Pelatihan Menumbuhkan Karakter Siswa Sekolah Dasar Tanjung Sari Melalui Permainan Edukatif Sederhana di SD Tanjung Sari, Magelang Jawa Tengah" telah dilaksanakan pada tanggal 25-26 Februari 2019. Kegiatan pengabdian ini dilaksanakan selama dua hari dimana masing-masing berlangsung selama 2 jam dari pukul 08.00-10.00 WIB bertempat di perpustakaan SDN Tanjung Sari, Magelang Jawa Tengah. Kegiatan pengabdian yang telah dilaksanakan mengutamakan penanaman karakter siswa SDN Tanjung Sari Magelang, Jawa Tengah melalui berbagai jenis permainan sederhana.

\section{Hari Senin, 25 Februari 2019}

Pada kegiatan hari pertama ini, pengabdian diawali dengan penyuluhan materi tentang pendidikan yang membentuk karakter, diberikan oleh ketua tim Ibu Dra. Rahmiati, M.Psi. yang telah biasa melakukan kegiatan yang berkaitan dengan karakter anak karena sesuai dengan bidang Beliau yang berkaitan dengan psikologi anak. Pada hari pertama kegiatan pengabdian yang berkaitan dengan materi membentuk karakter yang berkaitan dengan permainan sederhana. Setelah materi selesai guru-guru membuat kelompok dan diberikan kesempatan untuk merancang permainan sederhana yang akan dilakukan didalam kelas.

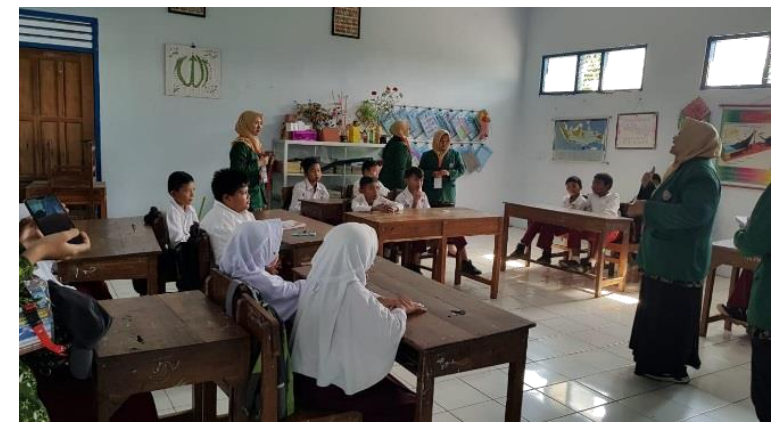

Gambar 1. Contoh Praktek Kegiatan Penerapan Permainan Edukatif dalam Kelas

Menurut Mutiah (2010) yang menjelaskan bahwa permainan dan bermain memiliki banyak fungsi yaitu: 1) sebagai sarana menumbuhkan kemampuan sosialisasi pada anak, memungkinkannya berinteraksi dengan lingkungan sosial yang dapat mengajarkannya mengenal dan menghargai orang lain, 2) sebagai sarana 
mengembangkan kemampuan dan potensi anak yang memungkinkannya mengenali berbagai macam benda, mengenali sifatnya, serta peristiwa yang terjadi di lingkungannya yang dapat menstimulasi kemampuan fantasi anak, dan 3) sebagai sarana mengembangkan emosi anak yang dapat menimbulkan rasa gembira, senang, tegang, puas, ataupun kecewa, sehingga mereka dapat menghayati berbagai rasa yang dirasakan ketika bermain.

Hal ini sesuai dengan tujuan yang ingin dilaksanakan dalam pengabdian ini dimana permainan dapat membuat siswa menjadi perduli terhadap lingkungan disekitar siswa, mampu mengembangkan potensi siswa selain kognitif, membuat siswa merasa termotivasi dalam belajar supaya lebih maksimal dalam belajar.

\section{Hari Selasa, 26 Februari 2019}

Pada kegiatan hari kedua ini tim pengabdian melaksanakan kegiatan di dalam kelas. Permainan yang dilakukan pertama adalah bermain tepuk bim bam pedi, dimana siswa dalam kegiatan bermain ini akan membentuk karakter yang berupa melatih konsentrasi siswa dan kepekaan terhadap sekitar. Pemainan tepuk bim bam pedi ini merupakan permainan yang sangat sederhana yang dapat membangkitkan motivasi siswa dalam belajar terutama di dalam kelas.

Permainan kedua adalah Talking stick. Arti dari Talking stick sendiri adalah tongkat bicara. Dimana tongkat ini berguna untuk menyampaikan informasi ataupun pertanyaan yang diberikan oleh guru. Permainan ini berguna untuk menanamkan karakter, diantanya; bertanggung jawab, konstrasi, dan membantu siswa mengingat. Dalam permainan sederhana yang hanya bermodalkan stick (tongkat kecil) yang dapat dibuat oleh guru dengan menggunakan sobekan kertas, guru dapat mengevaluasi setelah materi yang diajarkan dengan cara bermain Talking stick tersebut.

Permainan yang ketiga adalah kuda bisik. Berbeda dengan kedua permainan sebelumnya. Dalam permainan kuda bisik karakter yang dicapai adalah menjalankan amanah dan tanggung jawab. Sebab kunci utama adalah orang yang pertama membacakan informasi yang telah dibuat oleh guru kemudian menyampaikan kepada teman yang lainnya. Apabila ada kesalahan yang dilakukan oleh anggota kelompok maka dianggap gugur. Kekompakan juga terjalin walaupun segi kognitif didalam pemainan ini juga lebih diunggulkan karena harus memiliki daya ingat yang baik. Sehingga permainan ini cocok untuk menanamkan karakter karena keunggulan dari kuda bisik ini adalah daya ingat. 


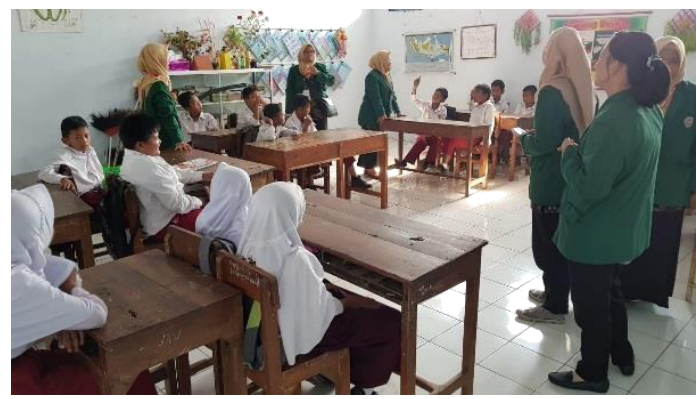

Gambar 2. Penerapan permainan Edukatif Kuda Bisik

Dari ketiga permainan diatas yang merupakan permainan yang cukup sederhana dapat di aplikasi kedalam kegiatan belajar mengajar baik didalam kelas maupun diluar kelas. Sehingga tidak hanya kesenangan semata yang didapatkan dalam permainan. Namun permainan mampu memberi manfaat yang besar bagi anak. Dan permainan jug dapat membuat mereka lebih memahami konsep (Prahmana, 2010). Hal ini karena sifat dasar anak-anak mudah memahami suatu pelajaran dengan cara bermain (Khobir, 2009). Tidak kalah pentingnya, permainan dapat membentuk anak menjadi seseorang yang memiliki karakter luhur. Pentingnya pembentukan karakter sejak dini dapat dilakukan dengan permainan tradisional (Hasiana, 2015). Seperti yang diungkapkan oleh Elissa (2017) mengenai permainan yang juga memiliki kelebihan dalam melatih kemampuan motorik, sikap, dan ketrampilan anak (Huda, 2018).

\section{KESIMPULAN}

Kegiatan pengabdian yang telah dilaksanakan menghasilkan beberapa kesimpulan, diantaranya; kegiatan "PKM Pelatihan Menumbuhkan Karakter Siswa Melalui Permainan Edukatif Sederhana di SDN Tanjung Sari, Magelang-Jawa Tengah" memberikan gambaran dan arahan kepada guru bahwa melakukan penanaman karakter siswa dapat melalui permainan edukatif yang bersifat sederhana dan tidak memerlukan banyak biaya.

Permainan sederhana yang bersifat edukatif ini memberikan kesempatan kepada siswa untuk belajar bekerja sama, kekompakan, toleransi, kejujuran, kedisiplinan, rasa ingin tahu, semangat kebangsaan, menghargai, kepemimpinan, kerja sama, peduli lingkungan, peduli social, tanggung jawab, religious, dan gemar membaca.

\section{UCAPAN TERIMA KASIH}

Ucapan terimakasih ditujukan kepada LPPM UHAMKA dan Program Studi PGSD UHAMKA yang memberikan dukungan sehingga kegiatan pengabdian masyarakat ini dapat terlaksana dengan baik. 


\section{DAFTAR PUSTAKA}

Abdullah, M. Y., Hastuti, W., \& Karmila, A. (2016). Lego ( Puzzle Bingo ) Games : Media Edukatif Berbasis Pendidikan Karakter Pada Anak Usia Sekolah Dasar Dalam Mewujudkan Generasi Indonesia Emas. Jurnal PENA, 2(1), 296-307.

Astini, B. N., Nurhasanah, Rachmayani, I., \& Suarta, I. N. (2017). Identifikasi Pemafaatan Alat Permaian Edukatif (Ape) Dalam Mengembangka Motorik Halus Anak Usia Dini. Jurnal Pendidikan Anak, 6(1), 31-40. https://doi.org/10.21831/jpa.v6i1.15678

Dalmeri. (2014). Pendidikan Untuk Pengembangan Karakter. Al-Ulum, 14(1), 269-288.

Dewi, T. U., \& Handayani, S. L. (2019). Penanaman Nilai Karakter Melalui Permainan Outdoor Bagi Anak-Anak Usia Dini. Publikasi Pendidikan, 9(1), 1-6.

Elissa, R. A. (2017). Permainan Tradisional sebagai Wadah Pembentukan Karakter Siswa Sekolah Dasar. Seminar Nasional Tahunan Fakultas Ilmu Sosial Universitas Negeri Medan, 421-424.

Hasiana, I. (2015). Mengembangkan Karakter Anak Usia Dini Melalui Permainan Tradisional. Jurnal Buana Pendidikan, 11(21), 21-26.

Huda, W. N. (2018). Pembentukan Karakter pada Siswa Sekolah dasar melalui Permainan Tradisional. Prosiding Seminar Nasional "Penguatan Pendidikan Karakter Pada Siswa Dalam Menghadapi Tantangan Global,” 243-247.

Khamalah, N. (2017). Penguatan Pendidikan Karakter di madrasah. Jurnal Kependidikan, 5(2), 200-215.

Khobir, A. (2009). Upaya Mendidik Anak Melalui Permainan Edukatif. Forum Tarbiyah, 7(2), 195-208.

Lickona, T. (1991). Educating for Character: How Our School Can Teach Respect and Responsibility. New York, Toronto, London, Sydney, Aucland: Bantam books.

Lickona, T. (2015). Mendidik untuk Membentuk Karakter (Terjemahan Abdu Wamaungo). Jakarta: Bumi Aksara.

Mutiah, D. (2010). Psikologi Bermain Anak Usia Dini. Jakarta: Kencana.

Prahmana, R. C. I. (2010). Permainan “Tepuk Bergilir” yang Berorientasi Kontruktivisme dalam Pembelajaran Siswa Kelas IV A di SDN 21 Palembang. Jurnal Pendidikan Matematika, 4(2), 61-69. 